\title{
Visualization of Silver-stained Chromosome Scaffold by Fluorescence Microscopy
}

\author{
Rekha Ghosh and Deepesh N. De \\ Applied Botany Section, Agricultural Engineering Department, \\ Indian Institute of Technology, Kharagpur West Bengal \\ 721302, India
}

Accepted March 3, 1993

That, in addition to DNA, a chromosome may contain a proteinaceous backbone was first suggested by Mirsky and Ris (1947) since removal of the DNA-histone complex by $\mathrm{NaCl}$ solution does not destroy the integrity of chromosomes. On the basis of electron microscopic observations of isolated chromosomes, Stubblefield and Wray (1971) demonstrated that the mitotic chromosomes consist of distinct axial and peripheral chromatin components. Paulson and Laemmli (1977) and Laemmli (1979) showed the existence of a scaffold protein. The first visualization of the scaffold at the level of light microscopy by silver-staining was done by Howell and Hsu (1979), and after that a number of workers confirmed their presence (SatyaPrakash et al. 1980, Haapala and Nokkala 1982, Rufas et al. 1982, Sentis et al. 1984, Nokkala and Nokkala 1985). Although some workers believe that the core is an artefactual product of the preparatory methods (Hadlaczky et al. 1981, Burkholder 1982), recently on the basis of their electron microscopic studies Zhao et al. (1991) stated that the scaffold is an inherent structure of the chromosome and not an artefact due to heterogenous dispersion of chromatin.

The present report deals with the visualization of the chromosome scaffold during meiosis of grasshopper Acrida turrita with the aid of a fluorescence microscope, after silver-staining followed by fluorochroming with acridine orange. The scaffold is discernible by bright-field microscopy as well as transmitted-light excitation.

\section{Materials and methods}

The spermatocytes from the testicular follicles of the local population of grasshopper Acrida turrita were used for the study. The follicles were dissected out and treated in the hypotonic saline solution $(0.075 \mathrm{M} \mathrm{KCl})$ for $20 \mathrm{~min}$, fixed in aceto-methanol (glacial acetic acid-absolute methanol $1: 3 \mathrm{v} / \mathrm{v}$ ) for $40 \mathrm{~min}$, placed in a drop of $45 \%$ acetic acid, minced and squashed. The cover glass was removed by inverting on $95 \%$ ethanol for overnight and rinsed thrice with the same to ensure that all acid was removed. The slides were finally rinsed in absolute ethanol and air-dried.

Following the method of Satya-Prakash et al. (1980) the air-dried slides were treated for varying periods $(5 \mathrm{sec}-3 \mathrm{~min}$ ) in $0.01 \mathrm{~N} \mathrm{NaOH}$ in $2 \times \mathrm{SSC}$ (prepared by mixing $6 \mathrm{ml}$ of $0.07 \mathrm{~N}$ $\mathrm{NaOH}$ to $40 \mathrm{ml}$ of $2 \times \mathrm{SSC}$ ) at room temperature. Then the preparations were washed successively in $2 \times \mathrm{SSC}, 70 \%$ ethanol and $95 \%$ ethanol and dried thoroughly. Following the technique of Pathak and Elder (1980), the slides were then stained in $\mathrm{AgNO}_{3}$ solution. For this, $2-3$ drops of $3 \%$ formalin were mixed thoroughly with $1 \mathrm{ml}$ of freshly prepared solution of $50 \% \mathrm{AgNO}_{3}$. A drop of this solution was placed on the slide, covered with a cover glass and incubated in a moist chamber at $65^{\circ} \mathrm{C}$ for $2-2.5 \mathrm{hr}$. The slides were cooled to room temperature and washed thoroughly with deionised water after removing the cover glass. The slides were air dried. 
The air-dried slides, previously stained by $\mathrm{AgNO}_{3}$, were fluorochromed with acridine orange (AO) (GT Gurr, London, CI 46005 Lot. No. 12811) following the method of Bertalanffy (1963) which is as follows. The slides were stained in $0.02 \%$ AO in 1/15 M Sörensen's phosphate buffer at $\mathrm{pH} 6.0$ for $4 \mathrm{~min}$ at room temperature followed by 3 successive washing in the same buffer for $5 \mathrm{~min}$ each and mounted in the buffer. The fluorescence microscope used was a Carl Zeiss Jena Fluoval fitted with a HBO 202 mercury vapour lamp as well as a filament lamp for white light. The microscope permits observation and photomicrography in transmitted as well as incident-light excitation and bright-field observation. The excitation filter

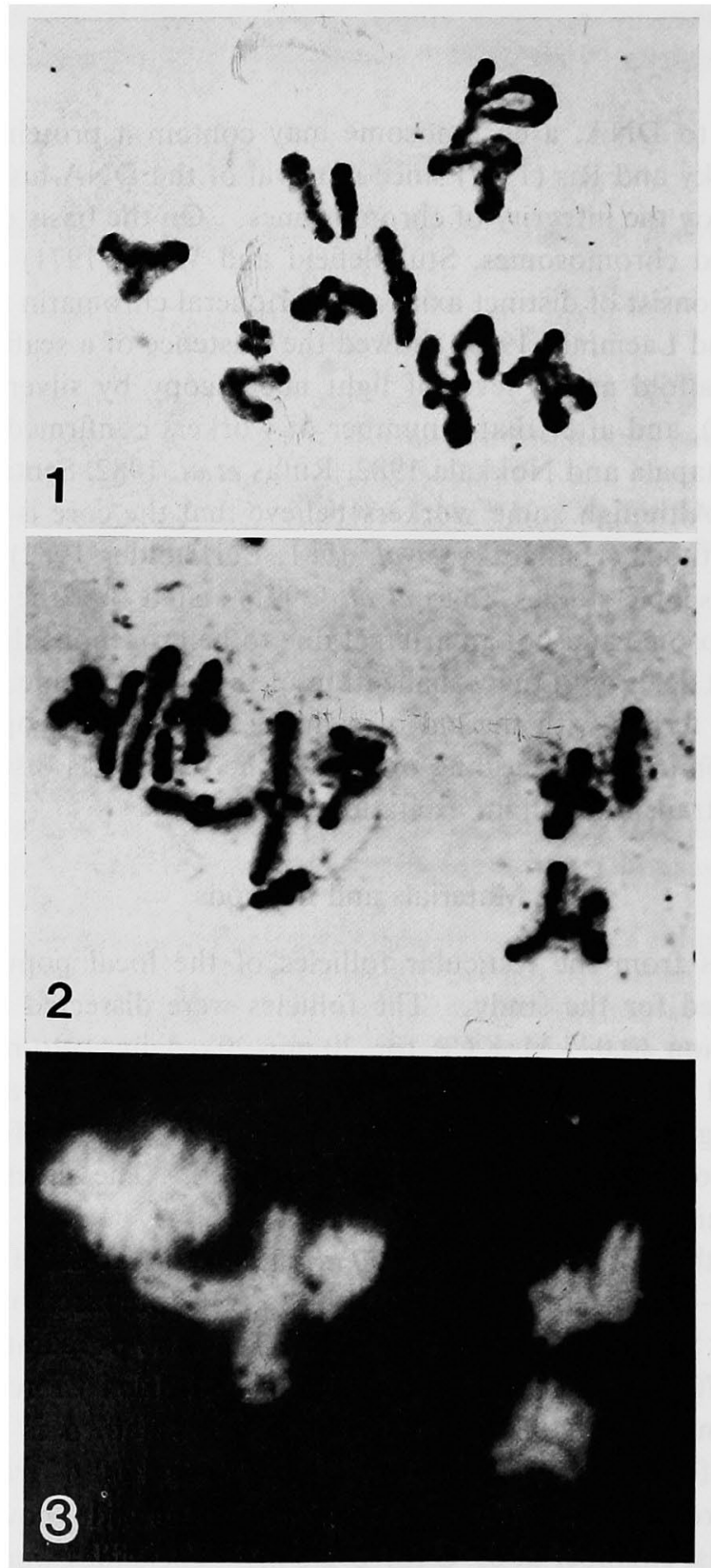

Figs. 1-3. 1, Diakinesis chromosomes exhibit prominent scaffold and epichromatin. $(\times 1,500)$. 2, Scaffold structure in metaphase I chromosomes. $(\times 1,700)$. 3, Same metaphase I chromosomes after silver-staining fluorochromed with acridine orange. Scaffold is very distinct with orange-red epichromatin. $(\times 1,700)$. 
BG $12 / 4 \mathrm{~mm}$ provides peak transmission at about $400 \mathrm{~nm}$ and the barrier filter $\mathrm{G} 249$ (OG $1 / 1)$ (yellow) permits transmission of all wave lengths above $546 \mathrm{~nm}$.

\section{Results and discussion}

The method of alkali treatment and silver-staining as recommended by Satya-Prakash et al. (1980) worked reproducibly for the present material when the alkali $2 \times \mathrm{SSC}$ treatment was made strictly for 100-110 sec. The diakinesis (Fig. 1) bivalents exhibit distinct scaffold extending from one end to the terminal heterochromatin which is black due to heavy deposition of silver. At metaphase I (Fig. 2) the scaffold is as black as the heterochromatin, contrasted against the thin layer of epichromatin which is brown. When the same silver-stained preparations were subsequently stained with $\mathrm{AO}$ are veiwed under transmitted-light excitation (Fig. 3) the scaffold was very distinct and appeared as dark red/brown and the epichromatin was visible by orange-red fluorescence. The orange-red appearance of epichromatin and dark red appearance of scaffold suggests superimposition or interference by silver on DNA fluorescence.

The hypotonic treatment is known to bring about general spreading of chromosomes and prolonged treatment is known to disperse epichromatin (Howell and Hsu 1979). The fixation in aceto-methanol is likely to remove a large quantity of histone, as De (1961) reported that fixation in aceto-ethanol removes considerable amount of histones from chromatin and Brody (1974) showed that it removes upto $80 \%$ of total cellular histones. Similarly, squashing in $45 \%$ acetic acid may remove an additional amount of histone, as Dick and Johns (1968) recorded that it extracts approximately $55 \%$ of total histone from calf-thymus deoxyribonucleoprotein. Thus a squash preparation must have lost a major quantity of histone, with concomitant chromosome swelling. The treatment of such a dehistonised chromosome with alkali SSC would obviously denature all DNA with nonhistone remaining mostly unaffected. Then under appropriate condition, nonhistone induces staining with silver nitrate and appears as a scaffold. Thus the view that the epichromatin consists of DNA- histone and scaffold is nonhistone with some amount of DNA is supported by the present study.

Satya-Prakash et al. (1980) recorded that the scaffold structure appeared to be disintegrating from diplotene to metaphase II, which indicated that a drastic change in chromosome organization is under way in meiosis. The scaffold is best revealed in diakinesis and metaphase I because the epichromatin may be made comparatively lax and spread out by the various treatments and the scaffold is ideally compact for silver deposition. In contrast, in the early stages of meiosis the scaffold is too tenuous to induce appreciable silver deposition. The scaffold is visible in the transmitted-light excitation, because the fluorescence of epichromatin below the scaffold is hindered or modified by the silver deposition of the scaffold and the part of the epichromatin directly above the scaffold is not adequately excited. Thus from the present study it may be concluded that chromosome scaffold consists of a non-histone protein to which DNA is attached as epichromatin.

\section{Summary}

The silver-stained chromosomes are observed under a fluorescence microscope with transmitted-light excitation after fluorochroming with acridine orange. The difference between the scaffold and epichromatin becomes accentuated due to fluorescence of denatured DNA. It is concluded that the scaffold is surrounded by epichromatin which contains DNA. 


\section{References}

Bertalanffy, L. Von. 1963. Acridine Orange fiuorescence in cell physiology, cytochemistry and medicine. Protoplasma. 57: 51-83.

Brody, T. 1974. Histones in cytological preparations. Exp. Cell Res. 85: 255-263.

Burkholder, G. D. 1882. Dansyl choride-stained nucleolar organizer and core like structures in chinese hamster metaphase chromosomes. Exp, Cell Res. 142: 485-489.

De, D. N 1961. Autoradiographic studies of nucleoprotein metabolism during the division cycle. Nucleus 1: $1-23$.

Dick, C. and Johns, E. W. 1968. The effect of two acetic-containing fixatives on the histone content of the calf thymus tissue. Exp. Cell Res. 51: 628-632.

Haapala, O. and Nokkala, S. 1982. Structure of human metaphase chromosomes. Hereditas 96: 215-228.

Hadlaczky, G. Sumner, A. T. and Ross, A. 1981. Protein-depleted chromosomes. I. Structure of iolated protein-depleted chromosomes. Chromosoma 81: 537-555.

Howell, W. M. and Hsu, T. C. 1979 . Chromosome core structure revealed by silver staining. Chromosoma 73: 61-66.

Laemmli, U. K. 1979. Levels of organisation of the DNA in eucaryotic chromosomes. Pharmacol, Rev. 30: 469-476.

Mirsky, A. E. and Ris, H. 1947. The composition and structure of isolated chromosomes. J. Gen. Physiol. 31: $1-18$.

Nokkala, S. and Nokkala, C. 1985. Mitotic and meiotic behaviour of axial core structure of holokinetic chromosomes. Hereditas 103: 107-110.

Paulson, J. R. and Laemmli, U. K. 1977. The structure of histone depleted metaphase curomosomes. Cell 12: 817-828.

Pathak, S. and Elder, F. F. B. 1980. Silver stained accessory structures on human sex chromosomes. Hum. Genet. 54: 171-175.

Rufas, J. S. Gimenez-Martin, G. and Esponda, P. 1982. Presence of a chromatid core in mitotic and meiotic chromosomes of grasshopper. Cell Biol. Int. Rep. 6: 261-267.

Satya-Prakash, K. L. Hsu, T. C. and Pathak, S. 1980. Behaviour of the chromosome core in mitosis and meiosis. Chromosoma 81: 1-8.

Sentis C, Rodriguez-Campos A, Stockert J. C. and Fernández-Piqueras J. 1984. Morphology of the axial structures in the neo-XY sex bivalent of Pycnogaster cucullata (Orthoptera) by silver impregnation. Chromosoma 90: 317-321.

Stubblefield, E. and Wray W. 1971. Architecture of the Chineșe hamster metaphase chromosome. Chromosoma 32: 262-294.

Zhao, J. Hao, S. and Xing, M. 1991. The fine structure of the mitotic chromosome core (scaffold) of Trilophidia annulata. Chromosoma 100: 323-329. 